Jouni Westling, University of Helsinki

Marko Laaksonen, Defense Command, Finnish Defense Forces

Aki Huhtinen, National Defense University, Helsinki, Finland

\title{
STRATEGY AS DISCURSIVE CONSTRUCTION IN THE FINNISH DEFENCE FORCES
}

\begin{abstract}
This paper draws upon critical discourse analysis to analyse an empirical study of strategy practices in a military organization. The recent practice-turn in strategy research emphasizes the meaning of discourses, routines and activities in a strategy formation process. Strategy is not understood only as an attribute of an organization, but also as activity; it is something people do and say or leave undone and unspoken. Research concerning strategy practices has, however, ignored military organizations and concentrated mainly on private enterprises and public administration. In this paper we argue that there is a need for a practice-turn in the military context as well. Just as practice theory has proven its usefulness in examining corporate strategies, it can also contribute to our understanding of the actual strategy process in military organizations and help us understand the practices behind formulated strategy.

We focus on the high-level strategic planners in the Finnish Defence Forces and analyse their conceptions of the strategy process. Based on the data of 14 in-depth interviews, the paper's goal is to analyse the discursive elements of strategy talk in a military organization. This paper will concentrate on three central issues. (1) What is the relationship between civil and military strategists while formulating strategy in a military organization? (2) Who are defined as strategists? (3) Are the high-level strategy planners aware of a variety of hidden agendas and power relations that shape the strategy formulation process? Although the discourses and practices we have found are, of course, context-specific, we claim that similar kind of strategic
\end{abstract}


discourses and practices can be found in other military organizations and possibly even in non-military organizations.

Research on civil-military relations has traditionally concentrated on examining the interaction between civil and military organizations but neglected the interaction within these organizations. Our study shows that formulating strategy in military organizations is a complex process far from the Clausewitzian conception that delimits the concept of strategy only to conventional war. Direction-setting, monitoring and allocation of resources are all outcomes of a constant debate between political, military, technological, economical and cultural aspects. Getting to know this kind of process can be beneficial for strategy researchers and managers working in the corporate field as well.

In addition, the Finnish Defence Forces constitute an interesting field for strategy research, as it is one of the three European armies that relies on compulsory military service. The fact that almost every male citizen has served guarantees a special position for this institution in society and particularly in strategy discourses.

\section{Keywords:}

Strategy as practice, discourse analysis, military strategy, civil-military relations

\section{Introduction}

This paper argues for a change of course in researching strategy in military organizations. The old Clausewitzian conception limits strategy only to conventional warfare and does not offer any help in developing and understanding strategy work on an organizational level. Recent study has, however, proved discourse analysis' usefulness (see e.g. Laine and Vaara, 2007; Samra-Fredericks, 2005) for scholars interested in organizational practices and the way strategy is formed and implemented by these practices. Our intent is to introduce practice theory 
and discourse analysis to closed military organizations that have traditionally remained outside the field of research.

Our research is based on 14 in-depth interviews of high level strategic planners in the Finnish Defence Forces (FDF). All interviewees have a long military background and they work in different parts of the FDF, offering a comprehensive view to strategy work in a military organization. Interviews were conducted in 2007 and they lasted between 35 minutes and two hours. Taking into consideration the relatively small amount of strategic planners in the FDF, our sample is big enough for this kind of research and allows us to draw plausible conclusions.

We managed to discover three discursive practices that had fundamental significance in the interviewees' strategy talk. These three form the key themes of this article; the relationship between a civil and military strategist, who is defined as strategist and the possible hidden agendas in strategy work. We will begin by presenting the theoretical framework and advance then to the above-mentioned themes.

\section{Strategy as practice}

The central idea of strategy as practice is to view strategy as a normal social phenomenon. Strategy is not something organizations have but something they do (Whittington 2004). Managerial actors in the different layers of organization contribute to strategy formulation and implementation in their daily practices and activities. The image of a sovereign top manager or team of top managers formulating a strategy is discarded since the significance of middle managers, consultants, strategic planners etc. is acknowledged. The concept of strategy formulation is also replaced by the concept of strategy work that refers to a wider sphere of action, than just planning.

Strategy can thus be examined as any other social phenomenon and the methodology and methods of social science can be applied to it (Whittington 2007). The Mintzbergian concept of the emergent nature of strategy has been an excuse to escape the research of strategy work for too long. Too little attention has been paid to the institutional context, like cultural values and politics of organization (Ezzamel and Willmott 
2004). There is an increasing pressure on researching the discourses and narratives which construct strategy.

Research concerning strategic management and the implementation of strategy has traditionally remained mostly on the macro-level of organizations. In addition strategy has been seen as a construction of a few variables that narrow down the field of strategic management and neglect the role of human actors (Jarzabkowski 2007). This old rational concept of strategy formulation and implementation, where strategy is seen as the final result of calculation of different competitive advantages, is rejected by the practice perspective as too abstract and impractical for the organization.

Instead, the focus of this paper is turned towards the actual practices that constitute the object of strategy. What are the strategists actually doing while strategizing and how are different tools like board meetings, away days, work groups, formal operating processes, technological devices etc. been exploited (Jarzabkowski 2004). In this article, practices refer to the general and shared routines, traditions, norms and processes that strategists use while strategizing.

The practice approach is interested in all the activities that affect to strategy work. As it is inspired by the "practice turn" in social sciences, the central focus is not on strategic activity itself but on the ways of strategizing in different organizations. Strategists perform regular patterns of activities that constitute certain practices. The objective is to find out what strategists work really is and break out from the positivistic traditions that have been dominating strategy research (Clegg et al. 2004).

This article considers strategy as a discourse that constitutes those actions and intentions from which it has initially been descended. Strategy is therefore an inseparable part of those practices which it is frequently thought to justify.

\section{Discourse analysis}

By discourse analysis we mean the research of the production of social reality through social practices, like language in-use, norms, 
ways of thinking and power. Taken into consideration that our interviewees form a rather homogeneous group, we are concentrating on analysing how they define certain attributes of strategy and strategic planning. The role of discourses, and their analyses, in modern warfare gives a good example of their significance in a military context, as well as in strategic planning.

Military language has traditionally been famous for defining events, items, etc. in very decisive and strict ways. The post-modern approach has challenged the old principle of keeping things simple and under control. 'War is peace' is a classic example of a slogan of language control, taken from George Orwell's 1946 essay 'Politics and the English Language'. 'Terror is war' is a post-modern example of a slogan that first kept the world and America together but later came to divide even Americans. Terrorists' attacks were remade linguistically from a crime scene to a war scene, and victims the of $9 / 11$ were defined as combat casualties. Language is a strategic weapon for leaders in war, who often use it as a mean of reinforcing unity and creating reality. Equally discourses in strategy work are creating a certain kind of reality.

The enactment of any large-scale project of political violence requires a significant degree of political and social consensus, and consensus is not possible without language. Normalising the practice of violence, requires the construction of a whole new language, or a kind of public narrative, that manufactures approval while simultaneously suppressing individual doubts and wider political protest. This new language is not simply an objective or neutral reflection of reality, nor is it merely accidental or incidental. Rather, it is a deliberately and meticulously composed set of words, assumptions, metaphors, grammatical forms, myths, and forms of knowledge. It is designated to achieve a number of key political goals. (Jackson 2005.)

For example the key element in constructing the overall narrative of the war on terrorism is based on the discursive creation of an external 'other' that reinforces the identity of the 'self'. The logic of the language in the war on terrorism predetermines the policy response; there is no other option but to fight back. At the same time, it makes anyone who opposes the policy appear like a coward who gives in to terrorism. 
(Jackson 2005.) These oppositions produce and reproduce our reality and similar kinds of contrasts can be found in strategy talk in the FDF.

After representing the basic features of a military organization and especially in the FDF, our goal is to analyse the found discursive practices from this theoretical perspective. The analysis will show, that the discursive practices are partly consequences of these features.

\section{Organization of the Finnish Defence}

\section{Forces}

The peacetime strength of the FDF is about 16,000 personnel. About 25,000 conscripts and 25,000 reservists are trained annually. The maximum wartime strength of the FDF is about 350,000 people. (FDF 2008.) For historical reasons the managing process in the FDF is dualistic in its nature. The process is divided into two chains of commands. The President of the Republic is the Commander-in-Chief of the Defence Forces. Direct operational command of the Defence Forces lies with the Commander of Defence Forces, who is subordinate to the supreme commander. In administrative matters the Defence Forces are subordinate to the Ministry of Defence (MOD). Roughly speaking the resources for the FDF comes from the MOD and the tasks from the Commander-inChief who has no power to affect on resources.

The position of the FDF in Finnish society is very strong and it is among the most respected institutions in Finland. About $80 \%$ of male citizens are still serving in the military and the people consider the WWII veterans as national heroes. According to the opinion polls people think very conservatively about the defence matters: they want to keep up the conscription and the independent non-alliance defence system. People also think that the main task of the FDF should be to defend Finland's own territory. (Laaksonen 2009.)

In the FDF one can find at least two explanations for the concept of strategy. The first one is the military-based Clausewitzian concept, which says that strategy is the employment of battles to reach the end of war. In other words, the military strategy is about using 
military power to win the war. In that sense, strategy cannot exist without war. The other way to define a strategy is loaned from the world of business and strategic management. The business strategy in the context of the FDF is mainly about creating the military capabilities in peace time. That is also the work that the interviewed strategic planners were doing. The creation of military capabilities consists of planning the future FDF organization, materiel and doctrine. It also includes the "marketing" of the needed resources to the politicians, media and the citizens. When comparing these two strategy concepts with the dualistic chain of command, one can conclude that the military strategy and the Commander-in-Chief form one entity in strategic and organizational sense whereas the business strategy and the MOD form another. The two strategies live in two different worlds. While the military strategy concentrates on winning the war, the business strategy lives in a world of public administration where budget savings, need for transparency, effectiveness and efficiency are elementary parts of everyday life. (Laaksonen 2009.)

\section{Relationship between civil and military strategists}

To understand the relationship between civil and military strategist in the FDF one must first realise that civilians and officers are in most cases working on different levels and areas in the field of national defence. The main convention is that civilians occupy the MOD and officers are the majority in the Defence Command and in the Services.

While discussing the relation of civilian strategists to military ones, there emerges an interesting discourse on the line between political and non-political action. Strategic planners with a military background and education in the Defence Command tend to define their work as nonpolitical.

"In the Ministry of Defence there are civilians who have close connections to political parties. [...] Whereas we in the Defence Command have only soldiers and we are looking things 
from an operative perspective, against our military professional background."

The standpoint of an officer participating in strategic planning is seen somehow more objective and it symbolises common interest, whereas the civilian actors are easily defined as biased and possibly even members of some interest group. If we look at the data from this perspective, there seems to be pressure to construct the identity and position of officers working on strategic planning, through binary oppositions that are rather common in this kind of compositions where separate groups attempt to differentiate each other. For instance, the following binary oppositions can be found in interviewees' comments when they talk about civilian and military actors in the strategic planning process: public interest - private interest, efficient planning - politically secure and rationality - ideological solutions. On the other hand, as we will later discover in this paper, these divisions turn out to be doubtful when they mix with the various hidden agendas inside the strategic planning process.

A similar situation with clear oppositions comes up more explicitly when the interviewees start to evaluate their relationship with purely political actors. By political actors we mean the Minister of Defence and the members of the Foreign and Security Policy Committee.

"The political side does not commit itself to anything except until the next election."

"Appropriateness, cost efficiency and other aspects of this kind can be ignored by regional policy."

Taking into account the extremely long planning cycles, that are a central problem in strategic planning in a military context, the possible reluctance to make, in a military sense, necessary but, from a political perspective, unpleasant decisions possesses naturally more problems than solutions for strategic planning. For instance, materiel procurement that constitutes a significant part of military budgets tends to 
have long planning and manufacturing periods before the equipment is even in operative use. In addition the life span of some materiel is counted in decades, which sets major challenges for planning. Reconciling the military needs in question with the political reality is defined as one of the fundamental stumbling blocks in strategic planning.

These two quotes above, however, represent at best the effort to construct the binary opposition. The possible political nature of strategy work in a military context is questioned and the associations of politics are mainly negative. The hegemonic conception of security and national defence is thus strongly shaped by this tension. Equally, just as many economical issues are every once in a while excluded from the political discourse as necessities, so are also military matters in many cases outside the political discourse for the same reason. On the other hand, Finland has chosen the way of divergence when it comes to the military, meaning officers remain politically neutral and cannot be members of any political party. This choice goes all the way back to Samuel Huntington's (1957) classical theory over civil-military relations and obviously reasserts the image of the division.

Question about the political position and role of officers in society is a classical theme in civil-military relations. Should they be integrated in to political life or remain neutral and not participate in political decision-making? (Feaver 1996.) The debate concerning both alternatives, convergence and divergence, is originated from the main problem of civil-military relations. How can we build an efficient, functional and subordinate army to a democratic society without endangering the democratic control of the military?

According to recent research, the Huntington's hypothesis of separate military and civil spheres in society does not exist. The risk of civilian rule being controlled or overthrown by the military is also minimal in old and stable democracies. On the contrary the intermingling of military and civil spheres is a far more relevant subject. (Burk 2002.) Research on strategy practices, when utilised in military context, has unique potential to combine strategy research with civil-military relations and open up the research for new areas. 


\section{Who is defined as strategist?}

Before analysing the discourse on who is defined as strategist in a military organization, we must first comprehend that there are many types of strategies in the FDF, as in any Army. These can roughly be divided into two groups; public and secret. As the first ones aren't necessarily the products of a comprehensive strategic planning cycle, we concentrate on the latter ones, or on the practices around them, to be exact. Being secret does not, however, mean that strategies remain that way forever, on the contrary, many strategic decisions and plans do come partly public when they become materialised, as an example a plan to buy new tanks and missiles or move to garrisons from one location to another.

The question about who is defined as strategist has close connections to the relationship of civilian and military actors in a strategy process. Another side must have the ultimate power to determine strategic guidelines. From the interviewees' perspective the power of democratic organizations to define the direction and content of strategy seems unquestionable.

"Of course we have to take the way the Ministry of Defence has paved to us"

"In the end these objectives and strategic directions are decided on a political level and not by state officials but by parliamentary decision-makers."

The whole discourse revolves around the fact that the political level is in charge and different military institutions are mostly implementing. This does not, however, mean that the military side would unresponsively content oneself with given resources and orders. It seems self-evident that the conception of possible threats, that are the base of strategy, is under constant debate, and all sides from the political parties to the services are trying to achieve a hegemonic position for their conception of threats and for the required performances in handling those threats. 
There is, however, an interesting contradiction between who is defined as a strategist and who gets the unofficial status of a strategic manager. Though strategic planners acknowledged the strict control of the parliament and its units over strategy work, they did not identify the Minister of Defence or any other member of the civil administration as the strategic manager or as a person who is responsible for strategic management. Inside the discourse of democratic control there is thus another discourse where the Commander of the FDF is designated as the strategic manager. His position in the strategy talk of the interviewees is remarkably sovereign. Regardless of the Commander of the FDF being nominated by President of the Republic and being subordinate to President, this example shows that the image of strategic leadership does not always follow organizational structure.

In addition to this distinction, another element of segregation seems to prevail inside the FDF. Officers working on strategic planning tend to see the normal staff working in garrisons and in lower positions as outsiders when it comes to strategy work.

"We don't want people from the performance rung to participate in strategy work, we already have too many experts." "It is not their business."

This chasm between strategic planning and implementing it manifests oneself clearly and it symbolises the most usual problem in military organizations. Doing strategy and putting it into practice are separated, in which case plans easily become too abstract and impractical, and the actual activity that should be lead by strategy is based on habitual practices. We are not declaring that these practices are categorically unwanted, but they certainly are not what was planned and intended for. If our goal is to move from planning and implementing of a strategy into understanding strategy work as a whole, there are some changes to be made. One must, however, remember that military organizations have some special characteristics, originating from their purpose, which cannot perhaps be completely fitted into models that are used in private and public sector. 


\section{Hidden agendas in strategy work}

We define a hidden agenda, in a context of strategic planning, as a conscious attempt to pursue a certain goal that is not known by others than its proponents or as a goal that is partly known but not officially presented as an objective. The fact that others might be aware of the existence of a hidden agenda does not make a difference as long as the content stays confidential. The purpose of these agendas is of course to have a certain desired influence on strategy.

Almost every interviewee had detected objectives of this kind or was sure about their existence in the strategic planning process. Despite the fact that the FDF operates in strict guidance of the MOD, the interviewees emphasised the continuous contest for resources between the different services. Although the struggle for resources was defined even as "a constant battle" the strategic planners could not identify especially gross cases. The existence of hidden agendas was regarded as "tolerable" or even "self-evident" but also "unfortunate". The whole idea of transparent resource allocation or strategic planning sounded improbable, though the goal was to create a process where isolated and hidden objectives of the different services did not have any significant role.

"Of course everyone there has hidden agendas [...] but I don't believe that they are such a big things".

From this point of view, hidden agendas are seen more as necessary evil than actual problems that could harm the outcome of strategic planning. Interviewees consider themselves as conscious actors in rational decision-making process which is mainly based on research and where occasional semi-secret goals, that are ran by small interest groups, have only minor significance.

On the other hand, hopes that all political, economical, ideological and technological aspects, that have effects on strategy, possibly even in the form of hidden agendas, could be identified and 
taken into consideration, are not justified. Strategic planners are operating in a fragmented field with only few actual players but also with myriad of varied inputs that are easily transformed to support some bias. Politicians afraid of closing a garrison in their electoral district, military industry marketing unnecessary weapon systems for the Army, budget cuts combined with rising prices of materiel, interpretations of the global security situation and foreign policy etc.

Secondly, if we take into account the fact that some interviewees considered public strategies, in the context of the FDF, predominantly as psychological operations, directed towards citizens, Members of Parliament and press, we can fairly ask following question: What is the role of psychological operations in the strategic planning process and on what level are they connected to possible hidden agendas? This could be a fertile research area for an ethnographer but for obvious reasons performing such a research is not conceivable.

However, one interesting dilemma that some interviewees ran into, was the asymmetry between these hidden agendas and conception of war that is at present based on two central doctrines. Effects Based Operations and Joint Forces form the base of the latest paradigm in science of war. Without analysing or defining these concepts closely we can sum them up by noting that the importance of huge war machinery has decreased and the significance of performance has increased. Rather than having certain amount of material and men, armies prefer establishing performance that is based on potential threats and protecting oneself from those threats. This performance can be constructed by stressing various areas of the society and the Army.

If the ultimate goal of strategic planning is to create desired performances, the entire idea of a hidden agenda becomes unnecessary or even counter-productive. Emphasizing performances has rather selfevident implications to strategy work.

"It forces the Services to think that if they do things like that, what effects does it have to the FDF as a whole."

"A problem might occur that we start fighting [about resources] and begin to resist the plans of the other services 
because they are so expensive and that money is always away from our projects"

In theory this kind of dispute about resources and territories should not exist since performances are the essential objectives that determine the course of decisions. According to the interviewees it has decreased but not disappeared since the FDF shifted to the new paradigm. However it is a good example of how change in external circumstances and in fundamental premises of the field is transformed into an organizational manoeuvre and practice to avoid needless controversy over resource allocation and the content of strategy.

\section{Conclusions}

This paper has attempted to show, that by concentrating on the discursive practices of strategy work in a military organization, it is possible to examine the features of strategy that are unattainable for traditional strategy research. Interesting micro-level practices, that have major impact on strategy work, can be analysed only if we expand the traditional area of strategy research and take the practice turn seriously. Even the found practices are in most cases considered context-specific, we claim, that they can also be found in other military organizations and even in large private enterprises. It would be surprising if strategic planners in other organizations would not use the same kind of methods of forming narratives about strategy and its construction. In addition the research at hand offers a more realistic picture of strategy work than one could get by reading through the documents where the FDF describes its strategy processes.

The second important discovery relates to the dualistic nature of military organizations. The relevant difference between military and other organizations is, that former operates in two different worlds and is obligated to be on one hand cost-effective, transparent and politically acceptable, and on the other hand capable of using effectively military power to win the war. These demands are based on the difference between the Clausewitzian conception of strategy and the vision of the 
new public management that is nowadays a constitutive part of defensive administration. They also form a fundamental contradiction that is the base of strategizing in military organizations. The interviewed strategic planners work in conjunction of these two worlds and therefore their work is far from the rational decision-making process, as we have pointed out. On the contrary, the strategy is under constant debate between political, military, technological, economical and cultural aspects. Although researching discursive practices in organizations does not instantly solve all the problems of strategic management, it is clear that ignoring those practices leads to too simplified conception of strategy.

From a military point of view one of the central future goals of strategy research is to solve the dilemma between civil and military spheres inside a military organization, since it constitutes the foundation for most of the problems in strategy work. If the continual failings of overly abstract and simplified strategic models are taken into consideration, the need for new tools in strategy research has become obvious. Thus the practice perspective offers a new approach into strategy in sense of research and it can indeed benefit the actual strategy work by increasing our awareness of how strategizing is really done. 


\section{References}

Burk, J. (2002) "Theories of Democratic Civil-Military Relations", Armed Forces \& Society, Vol. 29, No. 1, pp 7-29.

Clegg, S. R., Carter, C. and Kornberger, M. (2004) "Get up, I Feel Like Being a Strategy Machine", European Management Review, Vol. 1, No. 1, pp 21-28.

Ezzamel, M. and Willmott, H. (2004) "Rethinking Strategy: Contemporary Perspectives and Debates", European Management Review, Vol. 1, No. 1, pp 43-48.

Feaver, P. D. (1996) "The Civil-Military Problematique: Huntington, Janowitz, and the Question of Civilian Control", Armed Forces \& Society, Vol. 23, No. 2, pp 149-178.

The Finnish Defence Forces (2008) Facts about National Defence, Edita Prima Oy, Helsinki.

Huntington, S. P. (1957) The Soldier and the State. The Theory and Politics of Civil Military Relations. The Belknap Press of Harvard University Press, Cambridge.

Jackson, R. (2005) Writing the War on Terrorism: Language, Politics and Counter-terrorism, Manchester University Press, Manchester.

Jarzabkowski, P., Balogun, J. and Seidl, D. (2007) "Strategizing: The Challenges of a Practice Perspective", Human Relations, Vol. 60, No. 1, pp 527.Jarzabkowski, P. (2004) "Strategy as Practice: Recursiveness, Adaption, and Practices-in-Use", Organization Studies, Vol. 25, No. 4, pp 529-560.

Laaksonen, M. (2009) Merkillinen strategia. Puolustushallinnon strategian semioottinen tarkastelu, Edita, Helsinki.

Samra-Fredericks D. (2005) "Strategic Practice, Discourse and the Everyday Interactional Constitution of Power Effects", Organization, Vol. 12, No. 6, pp 803-841.

Laine, P. and Vaara, E. (2007) "Struggling Over Subjectivity: A Discursive Analysis of Strategic Development in an Engineering Group", Human Relations, Vol. 60, No. 1, pp 29-58.

Whittington, R. (2007) "Strategy Practice and Strategy Process: Family Differences and the Sociological Eye", Organization Studies, Vol. 28, No. 10, pp 1575-1586.

Whittington, R. (2004) "Strategy After Modernism: Recovering Practice", European Management Review, Vol. 1, No. 1, pp 62-68. 